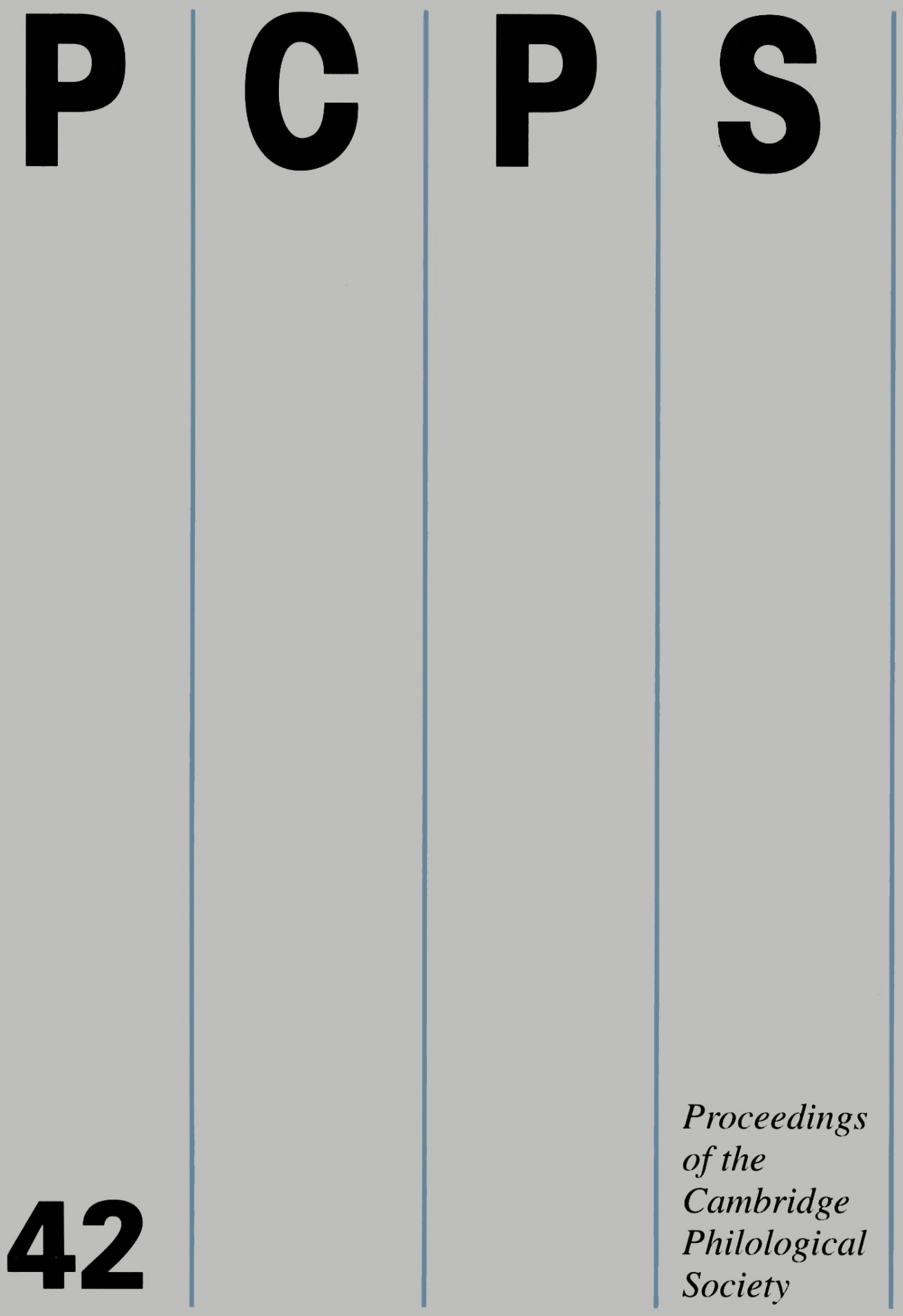




\section{OFFICERS OF THE SOCIETY}

1996-97

President:

\section{J. DIGGLE}

\section{Council:}

\section{F. L. AUSTIN (Treasurer),}

S. P. OAKLEY (Meetings Secretary),

J. S. WARING (Programme Secretary),

T. MORGAN, D. N. SEDLEY, S. VOUTSAKI

Editors of the Proceedings: P. R. HARDIE, S. P. OAKLEY

The objects of the Society are the furtherance of classical studies in general, and in particular the discussion and publication of critical researches into the languages, literature and civilisation of Greece and Rome.

Any person interested in the ancient world is eligible for membership. The subscription of a member resident in Cambridge is $£ 12.00$ annually, except that the subscription of a resident research student or senior member (aged 65 and over) is $£ 7.50$. The subscription of a member resident elsewhere is $£ 7.50$ annually. Members receive notices of all meetings of the Society and copies of the Proceedings.

Any library may subscribe to the Society and receive copies of the Proceedings. The subscription for libraries is $£ 15.00$ per annum.

The Society is responsible for two publications.

Proceedings of the Cambridge Philological Society, containing papers read to the Society and other articles, appears annually. The Editors welcome unsolicited contributions. Contributions intended for the Proceedings should be addressed to either Dr P. R. Hardie, New Hall, Cambridge CB3 ODF, or Dr S. P. Oakley, Emmanuel College, Cambridge CB2 3AP.

Supplements to the Proceedings is an occasional series designed to accommodate works of intermediate size, i.e. of about 150 pages. Proposals for monographs to be published in this series should be addressed to either of the Editors.

Applications for membership, and all other correspondence relating to the Society, should be addressed to Dr C. F. L. Austin, Trinity Hall, Cambridge CB2 1TJ. 